\title{
A Novel Ovine ex vivo Arteriovenous Shunt Model to Test Vascular Implantability
}

\author{
Haofan Peng ${ }^{\mathrm{a}}$ Evan M. Schlaich ${ }^{\mathrm{a}}$ Sindhu Row ${ }^{\mathrm{a}}$ Stelios T. Andreadis ${ }^{\mathrm{a}, \mathrm{b}, \mathrm{d}}$ \\ Daniel D. Swartz ${ }^{c, d}$
}

Departments of ${ }^{\mathrm{a}}$ Chemical and Biological Engineering, ${ }^{\mathrm{b}}$ Biomedical Engineering and ${ }^{\mathrm{c} P e d i a t r i c s, ~ W o m e n ~ a n d ~}$ Children's Hospital of Buffalo, and d Center of Excellence in Bioinformatics and Life Sciences, University at Buffalo, State University of New York, Buffalo, N.Y., USA

\section{Key Words}

Animal model - Cardiovascular endothelium .

Cardiovascular system $\cdot$ Mechanobiology $\cdot$ Methods of evaluation - Tissue engineering • Vascular biology •

Small intestinal submucosa $\cdot$ Thrombogenicity

\section{Abstract}

The major objective of successful development of tissue-engineered vascular grafts is long-term in vivo patency. Optimization of matrix, cell source, surface modifications, and physical preconditioning are all elements of attaining a compatible, durable, and functional vascular construct. In vitro model systems are inadequate to test elements of thrombogenicity and vascular dynamic functional properties while in vivo implantation is complicated, labor-intensive, and costineffective. We proposed an ex vivo ovine arteriovenous shunt model in which we can test the patency and physical properties of vascular grafts under physiologic conditions. The pressure, flow rate, and vascular diameter were monitored in real-time in order to evaluate the pulse wave velocity, augmentation index, and dynamic elastic modulus, all indicators of graft stiffness. Carotid arteries, jugular veins, and small intestinal submucosa-based grafts were tested. SIS grafts demonstrated physical properties between those of carotid arteries and jugular veins. Anticoagulation proper- ties of grafts were assessed via scanning electron microscopy imaging, en face immunostaining, and histology. Luminal seeding with endothelial cells greatly decreased the attachment of thrombotic components. This model is also suture free, allowing for multiple samples to be stably processed within one animal. This tunable (pressure, flow, shear) ex vivo shunt model can be used to optimize the implantability and long-term patency of tissue-engineered vascular constructs.

Copyright $\odot 2011$ S. Karger AG, Basel

\section{Abbreviations used in this paper}

AIx augmentation index

aPTT activated partial thromboplastin time

BAEC bovine aortic endothelial cells

DMEM Dulbecco's modified Eagle's medium

Em elastic modulus

FBS fetal bovine serum

$\mathrm{H} \& \mathrm{E} \quad$ hematoxylin and eosin

INR international normalized ratio

PBS phosphate-buffered saline

PWV pulse wave velocity

SEM scanning electron microscopy

SIS small intestinal submucosa

\section{KARGER}

๑) 2011 S. Karger AG, Basel

Fax +4161306 1234

E-Mail karger@karger.ch

www.karger.com
Accessible online at: www.karger.com/cto
Dr. Daniel D. Swartz

Department of Pediatrics, Women and Children's Hospital of Buffalo

University at Buffalo, State University of New York

124 Sherman Hall, Buffalo, NY 14214 (USA)

Tel. +1 716829 2536, E-Mail swartzda@buffalo.edu 


\section{Introduction}

More than 80 million people in USA suffered from cardiovascular disease in 2007. Autologous and allogeneic grafts have been the most promising solution for vascular replacement surgery. However, the availability of grafts is limited, especially for elderly donors who are more likely to suffer from cardiovascular disease. Polymeric scaffolds such as synthetic polytetrafluoroethylene (PTFE), polyglycolic acid (PGA), and polyurethane have been used with varying degrees of success in large diameter vessel implantation [Salacinski et al., 2001; Tiwari et al., 2002; Seifalian et al., 2003; Kannan et al., 2004; Lin et al., 2004; Vara et al., 2005; Torikai et al., 2008; Dahl et al., 2011]. Natural biopolymers, such as collagen and fibrin, support enhanced cellular functions but lack adequate mechanical strength for arterial implantation [Swartz et al., 2005; Yao et al., 2005, 2008; Isenberg et al., 2006; Shaikh et al., 2008]. On the other hand, native decellularized tissues such as arteries and small intestine submucosa (SIS) demonstrate sufficient mechanical strength and may provide inherent biological signals to guide tissue repair and remodeling [Huynh et al., 1999; Nemcova et al., 2001; Conklin et al., 2002; Gui et al., 2009; Tottey et al., 2010]. Regardless of the cell source or material, the difficulty in engineering vascular substitutes lies in matching the appropriate mechanical properties of bioactive materials with desirable blood compatibility and immunity characteristics, which are essential for longterm patency [Dahl et al., 2011; Desai et al., 2011].

Endothelial cell seeding or antithrombogenic luminal surface coating has been used to avoid platelet attachment and thrombus formation [Robotin-Johnson et al., 1998; Conklin et al., 2002; Wu et al., 2007; Hashi et al., 2010]. Thrombosis initiates from a subconfluent or damaged endothelium that exposes the underlying collagen matrix leading to platelet activation and fibrin clot formation [Brass et al., 2008]. In vitro, thrombogenicity of biomaterial is typically tested by adding platelets and/or citrated/heparinized whole blood onto the material's surface under static conditions. This method is limited due to its shear-free environment as platelets are highly activated by shape deformation due to local shear variation. Others have used a chandler loop, which provides a motional kinetic test of the hemodynamics. These tests can control shear stress but cannot reveal the real physiological environment, in which pressure, pulsation, and a full complement of blood components are all involved [Inauen et al., 1990; Tepe et al., 2006; Chin-Quee et al., 2009].

Ex vivo Vascular Tissue Engineering
Implantation of grafts into an animal model can better test the compatibility with shear-dependent coagulation, immunity response, and long-term remodeling potential. After implantation, Doppler ultrasound and angiography are generally applied to evaluate graft patency in terms of dilation, aneurysm formation, and anastomotic stenosis. However, these imaging modalities are limited in resolution and cannot be used to identify cellular level thrombogenic events such as platelet attachments [Hingorani et al., 2007]. In addition, implantation is limited to sophisticated suturing techniques, pre- and postsurgical animal care, and the use of multiple animals. Implantation could be labor-intensive and cost-ineffective, making it less attractive to test vascular implantability. Our previous studies demonstrated the development of functional and mechanical robust arterial substitutes made from hair follicle-derived smooth muscle cells and SIS [Liu et al., 2008; Peng et al., 2010b]. Our pilot implantation studies showed that in vitro mechanical optimization does not necessarily satisfy stringent in vivo criteria due to complication of coagulation and immunity response (data not shown). Luminal surface defects, surgical damage, anastomosis sites, and anticoagulation medication can all contribute to acute vascular graft failure [Grines et al., 2007; Yoshikai et al., 2007]. In addition, compliance mismatch between implanted grafts and the native vessels correlated with hyperplasia, stenosis, and an enhanced risk of graft failure in long-term implantation studies.

The lack of a physiologically relevant model to test the implantability of tissue-engineered vessels prompted us to develop an ex vivo model to evaluate and optimize the development of vascular grafts before implantation. Specifically, we developed an ex vivo arteriovenous animal model that utilizes bioreactor chambers in an arteriovenous flow loop circulated with whole blood under a physiological flow rate, pressure, and pulsation. This model was used to examine SIS-based grafts that were circularized with fibrin glue and exhibited mechanical properties similar to those of native carotid artery. The grafts were cultured in a bioreactor statically or under flow-induced shear before they were placed into an arteriovenous shunt loop. Multiple SIS-based grafts and control tissues (native carotid arteries and jugular veins) were sequentially and individually tested in the loop to assess their thrombogenicity and mechanical properties. Dynamic measurements of vessel diameter, pulsatile pressure, and flow rate were recorded in real time to analyze the pulse wave velocity (PWV), augmentation index (AIx), and elastic modulus (Em), which are clinical-

Cells Tissues Organs 2012;195:108-121 
ly recognized as indicators of vascular stiffness [Baguet et al., 2003; Nichols, 2005; Lane et al., 2006; Nichols et al., 2008; Sanz et al., 2009]. In addition, graft thrombogenicity was analyzed by scanning electron microscopy (SEM), histology, and immunostaining. In conclusion, this model system can be used to examine the initiation of acute thrombus formation and to measure dynamic mechanical properties of vascular grafts in a clinically relevant setting. As such it has the potential to significantly impact current research on engineering implantable vascular grafts by providing a rapid, cost-effective, and physiologically relevant system to evaluate design parameters such as stem cell sources, matrix materials, and mechanical preconditioning protocols on graft implantability.

\section{Material and Methods}

\section{Prefabricated SIS Graft}

Hydrated SIS sheets $(6 \times 5 \mathrm{~cm}$; Cook Biotech, West Lafayette, Ind., USA) were cut to obtain a rolled construct of 4 layers with an approximate diameter (inner diameter $4.5 \mathrm{~mm}$ ) and wall thickness $(0.8 \mathrm{~mm})$ similar to those of native carotid artery of adult sheep (3-5 years old). Various concentrations of fibrinogen were tested to optimize the graft fabrication to increase the burst pressure and maintain the tubular structure; 22, 11, and $5.5 \mathrm{mg} /$ $\mathrm{ml}$ fibrinogen (Enzyme Research Laboratories, South Bend, Ind., USA) and $125 \mathrm{U} / \mathrm{ml}$ thrombin (Sigma, St Louis, Mo., USA) were applied to each layer during assembly to glue the SIS layers together. The mandrels, made of polydimethylsiloxane (PDMS; Dow Corning, Midland, Mich., USA), were precoated with Dulbecco's modified Eagle's medium (DMEM) $+10 \%$ fetal bovine serum (FBS) to facilitate the detachment of SIS grafts after tubularization. The resulting grafts were polymerized at $37^{\circ} \mathrm{C}$ for 30 min to enhance fibrin polymerization. After polymerization, the grafts were gently detached from the mandrel. The two ends of the grafts were cut to exclude any incomplete layers and avoid interlayer separation.

\section{In vitro Measurement of Burst Pressure}

SIS grafts were cannulated and mounted into the bioreactor chamber (LumeGen Bioreactor; Tissue Growth Technologies, Minnetonka, Minn., USA). The Doppler ultrasound flow meter (Transonics, Ithaca, N.Y., USA) and pressure transducer (Tissue Growth Technologies) were connected. Fabricated grafts, 5-6 cm in length, glued by various fibrin concentrations were tested. The closed bioreactor loop was filled with phosphate-buffered saline (PBS) expelling all air from the circuit and pump. To measure the burst pressure, one end of the circulation loop was closed and PBS was infused at $500 \mathrm{ml} / \mathrm{min}$ until the graft material ruptured and the burst pressure was recorded.

\section{Cell Culture}

Bovine aortic endothelial cells (BAEC) were kindly provided by Dr. Kolega (Department of Pathology and Anatomical Sciences, University at Buffalo [Martins and Kolega, 2006]). Cells were cultured and maintained in DMEM $+10 \%$ FBS $+1 \%$ AA using $0.2 \%$ gelatin-coated culture dishes with a culture medium change every 3 days. BAECs were used between passages 12 and 18 .

\section{Static Seeding and Preconditioning Protocols}

In a sterile culture hood, the autoclaved bioreactor and flow loops were assembled (Tissue Growth Technologies) and fabricated grafts were placed into the chambers. BAECs were trypsinized and placed into the lumen of the graft $\left(2 \times 10^{6}\right.$ cells $\left./ \mathrm{ml}\right)$. Chambers were placed on a rotary shaker and rotated at $5 \mathrm{rpm}$ (Roto-Shake Genie Rotator; Scientific Industries, Inc., New York, N.Y., USA) for $8 \mathrm{~h}$. Following seeding, the grafts were incubated at $37^{\circ} \mathrm{C}$ for 7 days to enhance BAEC adherence and confluence. For presheared samples, chambers were connected to the flow system after 1 week of static culture. The flow rate was gradually ramped until the shear stress reached 6 dynes $/ \mathrm{cm}^{2}$, where it was maintained for another 2 days under physiologic pressure (100$120 \mathrm{~mm} \mathrm{Hg}$ ). The wall shear stress was calculated using the Hagen-Poiseuille equation:

$$
\mathrm{t}_{\mathrm{w}}=4 \frac{\mu \mathrm{Q}}{\pi \mathrm{R}^{3}}
$$

where $t_{w}=$ shear stress; $Q=$ volumetric flow rates; $\mu=$ viscosity of medium; $\mathrm{R}$ = radius of the grafts.

\section{Animal Care}

Procedures and protocols in this study were approved by the Institutional Animal Care and Use Committee (IACUC) of the State University of New York at Buffalo. A total of 3 adult female Dorset cross sheep between the ages of $4-5$ years and weighing $40-50 \mathrm{~kg}$ were used. In order to assess thrombogenicity, the grafts were exposed to blood in an ex vivo arteriovenous shunt model. Anesthesia was induced via pentothal sodium (50 mg/animal) and maintained with $1.5-2 \%$ isoflurane through a $6-\mathrm{mm}$ endotracheal tube using a positive pressure ventilator and $100 \%$ oxygen. Cyclosporine A (200 mg/day), aspirin ( $975 \mathrm{mg} /$ day), and warfarin sodium (20-30 mg/day; Barr Laboratories, Pomona, N.Y., USA) was given 5-8 days before the procedure. The international normalized ratio (INR) was monitored and maintained between 1.7 and 2.5 after 5-8 days of warfarin sodium (Alere Home Monitoring, Inc., Livermore, Calif., USA). Heparin (100 U/kg) was then administered intravenously to the animals $30 \mathrm{~min}$ prior to cannulation of the bioreactor tubing into the carotid artery and external jugular vein. Heparin was infused at a rate of $60 \mathrm{U} / \mathrm{kg} / \mathrm{h}$ throughout the surgery.

Heparin efficacy was determined by one-stage activated partial thromboplastin time (aPTT) assay. For aPTT, platelet-free plasma was incubated at $37^{\circ} \mathrm{C}$, and activator (platelin- $\mathrm{L}$ reagent) and $\mathrm{CaCl}_{2}$ were added to induce clotting. The clotting time was measured using a coagulometer (Coag-A-Mate XM; Organon Teknika Corporation, Durham, N.C., USA) kindly provided by Dr. Balu-Iyer and Dr. Peng in the department of Pharmaceutical Sciences, University at Buffalo (SUNY) [Peng et al., 2010a]. All animals were euthanized following the procedure with sodium pentobarbital $100 \mathrm{mg} / \mathrm{kg}$, i.v. (Fatal Plus).

\section{$P W V, A I x$, and Em}

The pressure and flow rate were monitored in real time, proximal to the grafts in the bioreactor chamber. The diameter of each 
graft was also measured in real time using an LED micrometer. These dynamic measurements were used to calculate the PWV and AIx.

PWV is defined as the distance traveled by the wave divided by the time needed for the wave to travel that distance:

$$
\mathrm{PWV}=\frac{\text { travel distance of wave }}{\text { time }}
$$

The path is the distance between the pressure transducer and the LED micrometer. The time is the difference between the upstroke of the pressure wave and that of the diameter wave.

The AIx is calculated from the pressure difference between the second systolic peak (Ps') and the inflection point (Pi) normalized to the difference between the diastolic pressure $(\mathrm{Pd})$ and the systolic pressure (Ps) [Nichols, 2005].

$$
\mathrm{AIx}=\frac{\mathrm{Ps}-\mathrm{Pi}}{\mathrm{Ps}-\mathrm{Pd}}(\%)
$$

The augmentation is due to the partial overlap of the front and reflected waves. The stiffer the grafts, the greater the amplitude and velocity of the reflected wave will be.

Finally, the Em is defined as the ratio of pressure change driving an increase in blood vessel diameter [Sanz et al., 2009].

$$
\mathrm{Em}=\frac{\mathrm{Ps}-\mathrm{Pd}}{\left(\mathrm{d}-\mathrm{d}_{0}\right) / \mathrm{d}_{0}}(\mathrm{~mm} \mathrm{Hg})
$$

\section{Thrombogenicity Test in an ex vivo Arteriovenous Shunt}

Model

The bioreactor chamber was positioned via a stainless steel stage (Tissue Growth Technologies) and primed with heparinized saline to ensure that no air was introduced into the vascular system. The pressure transducer and ultrasound flow probe were closely connected proximal to the grafts. A restrictor was used to clamp the tubing distal to the bioreactor chamber to adjust the flow rate to a native arterial level. The baseline heart rate, flow rate, and pressure were measured before placing the grafts in the arteriovenous shunt loop. Cannulae with the optimal diameter and design were placed into the carotid artery and jugular vein in order to prevent accidental vessel twisting and vasospasm (Biomedicus, Medtronic, Minneapolis, Minn., USA). The skin incision was closed and covered in order to maintain the temperature and vascular homeostasis, which could alter the flow rate and pressure. The abdominal aortic flow rate was also monitored as a reference of cardiac output. Grafts (mean length $5 \mathrm{~cm}$, mean internal diameter $4.5 \mathrm{~mm}$ ) were subjected to $20 \mathrm{~min}$ of blood flow [Yazdani et al., 2010]. The grafts were gently washed by $60 \mathrm{ml}$ heparinized PBS immediately following blood exposure to gently remove nonattached blood cells. Grafts were then pressure fixed with $10 \%$ formalin for $24 \mathrm{~h}$ and prepared for SEM, histology, and immunostaining.

\section{Histology and Immunostaining}

Pressure-fixed samples were dehydrated in a series of graded ethanol solutions and xylene substitute and then embedded in paraffin as reported previously [Geer et al., 2004]. In order to evaluate tissue development, $5-\mu \mathrm{m}$ sections were stained with Harris hematoxylin and eosin (H\&E). Immunostaining was performed using the following antibodies in PBS containing 5\% normal goat serum (Sigma): mouse anti-ovine CD41/61 (1:10 dilution, $30 \mathrm{~min}$ at room temperature; SeroTec, Raleigh, N.C., USA),
Alexa Fluor 546 Phalloidin (1:20 dilution, $20 \mathrm{~min}$ at room temperature; Invitrogen, Eugene, Oreg., USA), and Alexa Fluor 488 rabbit anti-mouse IgG (1:100 dilution, $1 \mathrm{~h}$ at room temperature, Invitrogen). Samples were counterstained with DAPI (Hoechst $33342 ; 10 \mathrm{mg} / \mathrm{ml} ; 1: 400$ dilution; $1 \mathrm{~min}$ at room temperature; EMD Biosciences).

\section{SEM and Quantification}

To analyze endothelial cell morphology and assess the luminal surface of the preconditioned grafts post hemodynamic exposure, scanning electron microscopy was utilized (SEM model SU-70; Hitachi Co., Tokyo, Japan). Briefly, samples were fixed in 10\% formalin solution for $24 \mathrm{~h}$. Samples were then dehydrated in a sequence of ethanol solutions $(15,35,50,75,95$, and $100 \%$ ethanol) for $5 \mathrm{~min}$ each and incubated in hexamethyldisilazane (HMDS; MP Biomedicals, Solon, Ohio, USA) for $15 \mathrm{~min}$. Clamps on two sides of the sample were applied to ensure the smoothness and flatness of the sample in order to facilitate staining and SEM picture acquisition. After air drying at room temperature, the samples were coated with a 20-nm layer of evaporated gold or carbon and images were analyzed for endothelial cell morphology, retention, and platelet attachment. Surface coverage by platelets, red blood cells, and fibrin mesh was quantified by manually contouring the platelet aggregates based on SEM images using Adobe Photoshop CS3 (Adobe, San Jose, Calif., USA). The percentage of area covered by thrombus was quantified by Image J (National Institutes of Health, Bethesda, Md., USA) and reported as an average of 5 representative fields of $\times 1,000$ images.

\section{Results}

\section{Fibrin-Glued SIS Exhibited a High Burst Pressure in vitro}

SIS sheets were circularized by wrapping around 4.5-mm-diameter mandrels manually. The cylindrical walls were composed of four layers of hydrated SIS that were fixed together with fibrin glue resulting in a wall thickness similar to that of native carotid artery (fibringlued SIS: $642.4 \pm 187.3 \mu \mathrm{m}, \mathrm{n}=7$; carotid artery: 799.3 $\pm 149.3 \mu \mathrm{m}, \mathrm{n}=6$, including adventitia; SIS only without fibrin: $332.1 \pm 135.6 \mu \mathrm{m}, \mathrm{n}=7$; artery without adventitia: $274.2 \pm 64.7 \mu \mathrm{m}, \mathrm{n}=6$ ) (fig. 1e). Following removal of the mandrel cylindrical SIS grafts maintained their shape and inner diameter (fig. la, b) similar to native adult ovine carotid artery (fig. 1c, d). The burst pressure increased significantly by about 3 -fold when the fibrin concentration increased from 5.5 to $22 \mathrm{mg} / \mathrm{ml}(5.5 \mathrm{mg} / \mathrm{ml}$ fibrin: $392.7 \pm 191.2 \mathrm{~mm} \mathrm{Hg}, \mathrm{n}=4 ; 11 \mathrm{mg} / \mathrm{ml}$ fibrin: $456.8 \pm 114.1 \mathrm{~mm} \mathrm{Hg}, \mathrm{n}=5 ; 22 \mathrm{mg} / \mathrm{ml}$ fibrin: $1,192.4 \pm$ $300.3 \mathrm{~mm} \mathrm{Hg}, \mathrm{n}=7, \mathrm{p}<0.01$ ) (fig. 2). The $22 \mathrm{mg} / \mathrm{ml}$ fibrin concentration was applied throughout remainder of the study. 


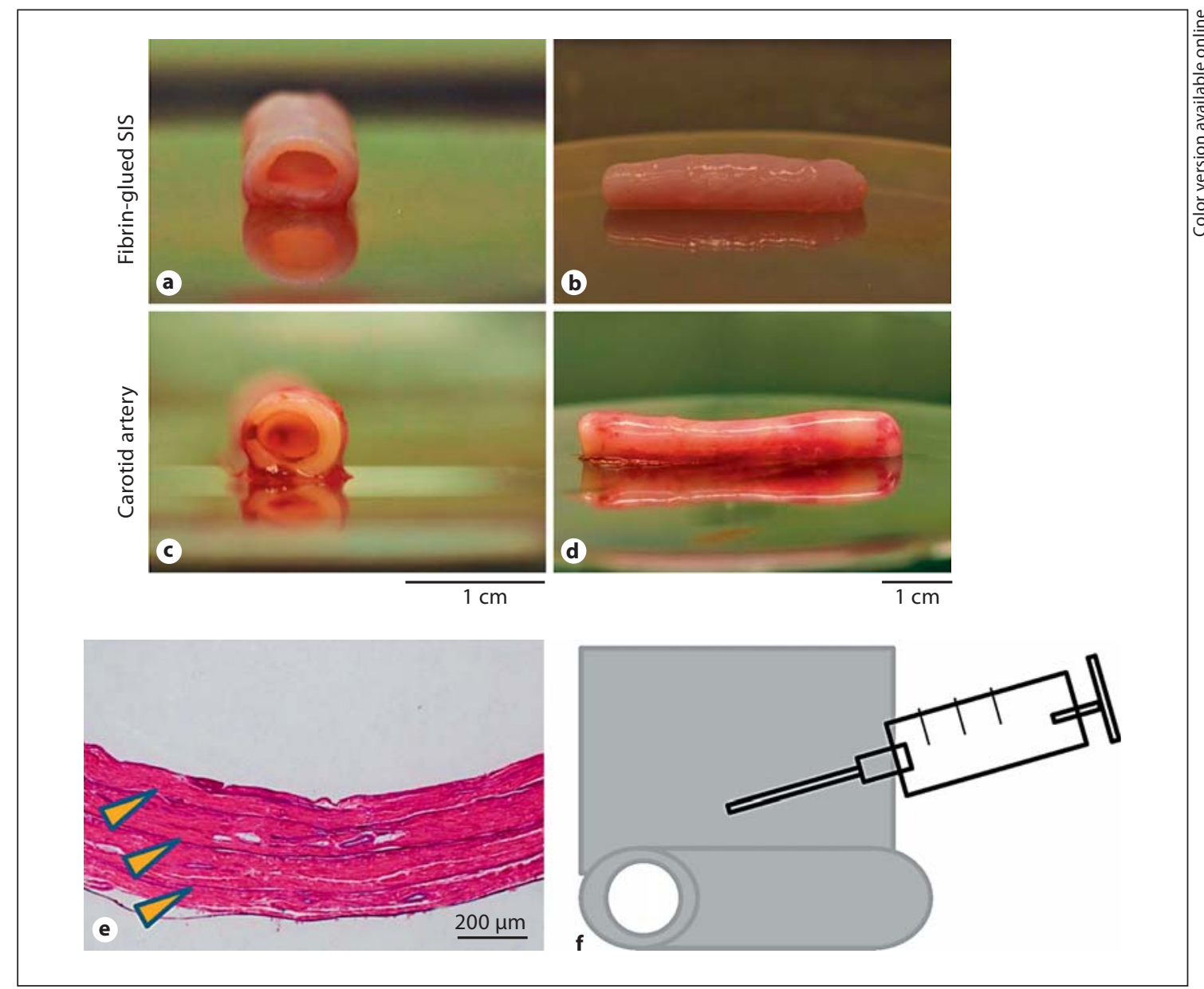

Fig. 1. Fabrication of the fibrin-glued SIS vascular graft. Fibrin-glued SIS vascular graft end view (a) and longitudinal view (b). Native ovine carotid artery end view (c) and longitudinal view (d). e H\&E-stained cross section of fibrin-glued SIS depicts four layers of SIS adhered with fibrin glue $(22.0 \mathrm{mg} / \mathrm{ml})$. Arrows indicate the interfaces between SIS layers. f Illustration of fibrin glue application on SIS. Fibrinogen was homogeneously spread on SIS and thrombin was added with a syringe as the layers were wrapped around the mandrel.

Fig. 2. The fibrin-glued SIS vascular graft showed increased burst pressure at higher fibrin glue concentrations. Fibrin glue was used at $5.5 \mathrm{mg} / \mathrm{ml}(\mathrm{n}=4), 11 \mathrm{mg} / \mathrm{ml}(\mathrm{n}=5)$, or $22 \mathrm{mg} / \mathrm{ml}$ $(\mathrm{n}=7)$. The asterisk denotes statistical significance between the indicated samples and those at the highest fibrin concentration of $22 \mathrm{mg} / \mathrm{ml}(\mathrm{p}<0.05)$.

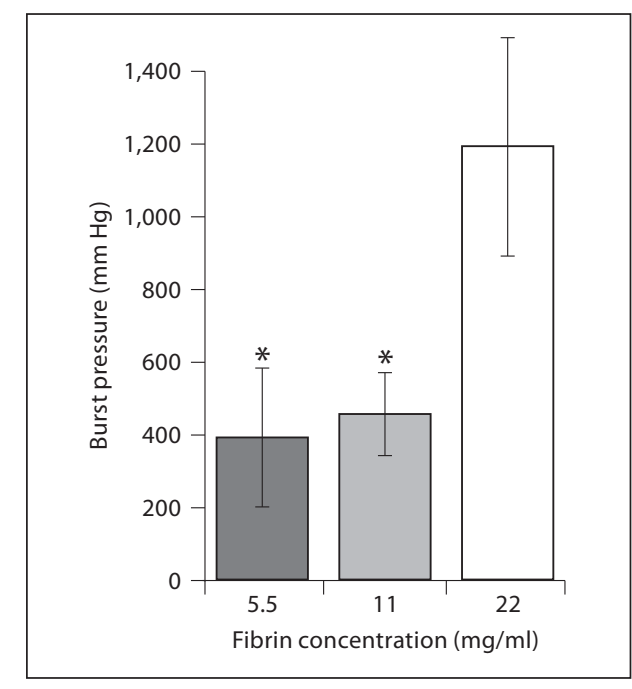




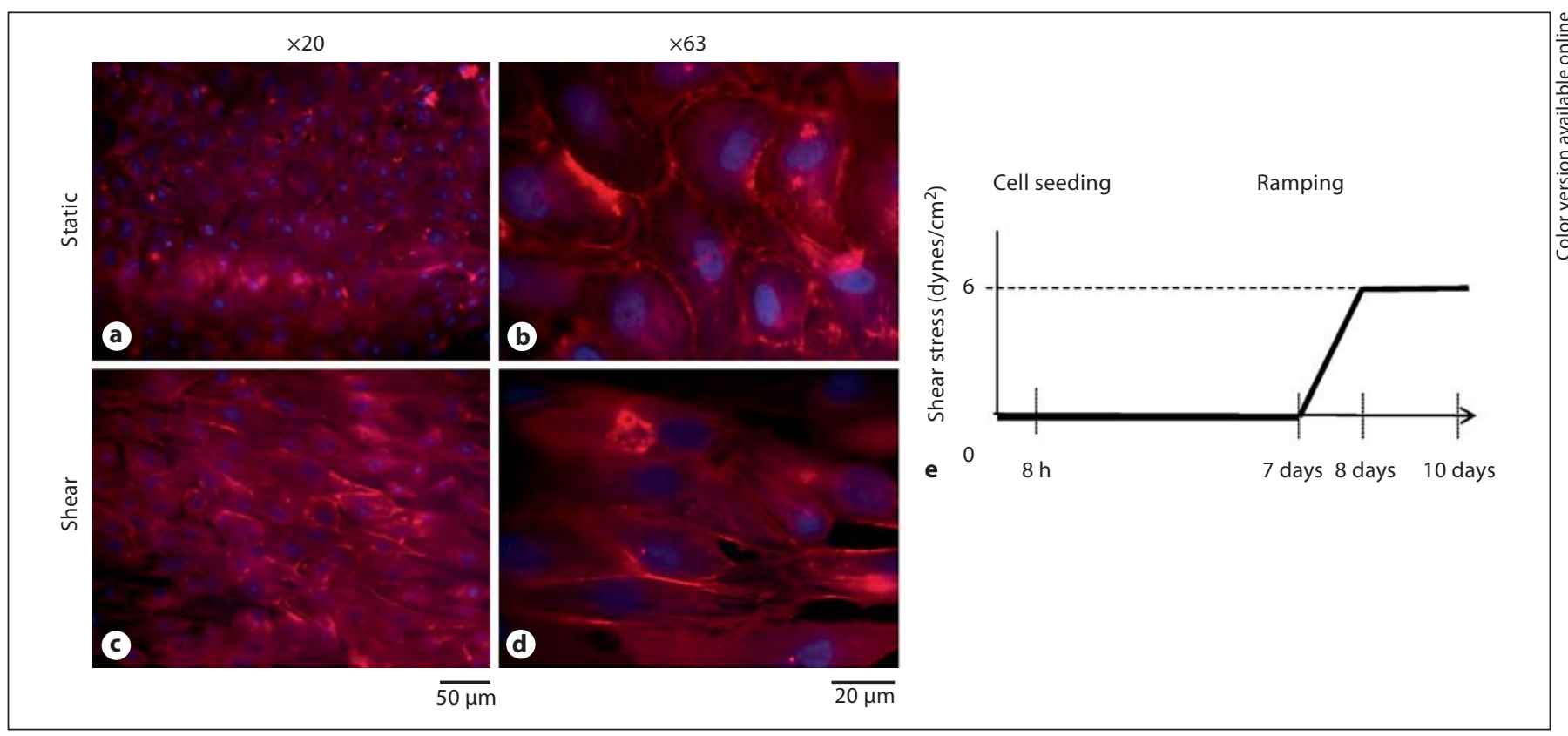

Fig. 3. Confluence and alignment of endothelial cells on the luminal surface of SIS. BAECs were seeded in the SIS lumen and cultured statically $(\mathbf{a}, \mathbf{b})$ or under shear $(\mathbf{c}, \mathbf{d})$ for 10 days. e Illustration of the shear ramping protocol: $8 \mathrm{~h}$ of seeding under rotation was followed by 7 days of static culture, ramping from 0 to 6 dyne $/ \mathrm{cm}^{2}$ within $24 \mathrm{~h}$ and keeping the grafts at that shear level for 2 additional days. Scale bars $=50 \mu \mathrm{m}(\mathbf{a}, \mathbf{c})$ and $20 \mu \mathrm{m}$ $(\mathbf{b}, \mathbf{d})$.
Endothelialization of SIS Grafts in a Static Culture or Presheared in a Bioreactor

BAECs $\left(2 \times 10^{6} / \mathrm{ml}\right)$ were seeded into the lumen of SIS grafts under rotation to enhance seeding homogeneity. After 7 days the cells showed a high level of confluence in the lumen. Low cell density areas at both ends of the grafts $(0.5 \mathrm{~cm})$ were excluded before the test. To compare the shear and static culture of BAECs, some grafts were exposed to shear stress gradually up to 6 dynes $/ \mathrm{cm}^{2}$ within $24 \mathrm{~h}$ under physiological pressure (around $100 \mathrm{~mm} \mathrm{Hg}$ ) and shear was maintained at the same level for 2 more days. As shown in figure $3 \mathrm{c}, \mathrm{d}$, under shear, cells became elongated and aligned in the direction of flow.

\section{Regulation of Blood Thrombogenicity by aPTT and INR}

Throughout the experiment we maintained an adequate dose regiment to test the thrombogenicity of the grafts without risking systemic coagulation during the surgical procedure. Heparin (100 U/kg bolus i.v. followed by $100 \mathrm{U} / \mathrm{kg} / \mathrm{h}$ infusion i.v.) took $20-30 \mathrm{~min}$ to take effect throughout the circulation. The effect of heparin and warfarin sodium administration on blood thickness was monitored by measuring the aPTT and INR, which were kept within the clinically recommended range, i.e. 1.82.5 times higher than normal [Connell et al., 2007]. Though warfarin sodium is typically an anticoagulation drug for long-term use, we included it in our protocol because it can be monitored by measuring the INR using a portable patient-friendly device. This represents clinical translation to what might be expected post implantation.

\section{Endothelialized Grafts Exhibited Better}

Anticoagulation Properties than SIS Matrix Alone

This physiologically relevant model allowed measurement of acute thrombus formation of multiple vascular grafts per animal. The highest number of grafts that was tested in a single animal was 8 , but in general this number varied depending on the maintenance of the blood pressure and heart rate of the animal. The carotid artery flow rate and diameter were about $200-300 \mathrm{ml} / \mathrm{min}$ and $5-7$ $\mathrm{mm}$, respectively ( $\mathrm{n}=5$ animals, age $3-5$ years). Following the arteriovenous shunt creation, the flow rate increased to $500-800 \mathrm{ml} / \mathrm{min}$ and the pressure dropped significantly to about $60 \mathrm{~mm} \mathrm{Hg}$. Therefore, the downstream restrictor was adjusted to decrease the flow rate to the original arterial flow level (fig. 4b). Notably, the pres- 


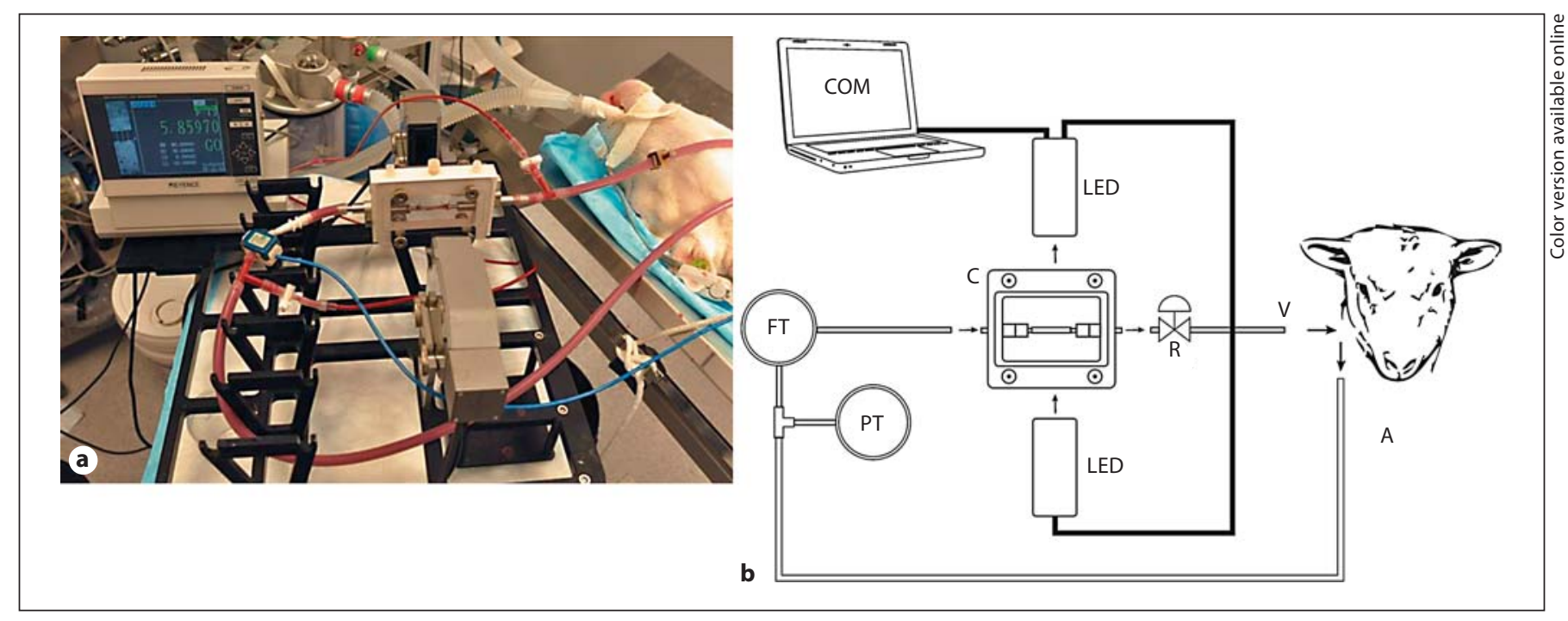

Fig. 4. Ovine arteriovenous shunt model. a Image of the arteriovenous shunt model. b Schematic of the arteriovenous shunt model. The endothelial cell-seeded, fibrin-glued SIS graft was mounted in a bioreactor chamber and connected in series with a pressure transducer, flow transducer, and laser micrometer. $\mathrm{A}=$ Carotid artery; $\mathrm{PT}=$ pressure transducer; $\mathrm{FT}=$ flow rate transducer; $\mathrm{C}=$ chamber (grafts); $\mathrm{R}=$ restrictor; $\mathrm{COM}=$ computer and digital reader; $\mathrm{LED}=\mathrm{LED}$ micrometer; $\mathrm{V}=$ jugular vein. sure was still between arterial and venous ranges probably due to anesthesia. The isoflurane was adjusted according to the animal response and hence it might have resulted in a different baseline pressure throughout the surgery (fig $5 \mathrm{a}, \mathrm{d}, \mathrm{g}$ ). The dynamic changes in the outer diameter of the vascular graft were monitored throughout the study (fig. 5c, f, i). The pressure and flow rate were also monitored in the abdominal aorta to ensure the stability of cardiac output (data not shown).

Graft Stiffness Evaluated by the PWV, AIx, and Em Using an ex vivo Arteriovenous Shunt Model

Clinically, blood vessel stiffness can be evaluated noninvasively by the PWV and AIx. In our arteriovenous shunt model, front waves were generated by heart pulsation and reflected by the downstream jugular vein back through the vascular graft. The PWV was: for veins, 3.17 $\pm 0.82 \mathrm{~m} / \mathrm{s}$; for SIS grafts, $7.25 \pm 0.90 \mathrm{~m} / \mathrm{s}$, and for arteries, $9.29 \pm 4.08 \mathrm{~m} / \mathrm{s}$ (each graft, $\mathrm{n}=3$; at least 2 waves were analyzed per graft). SIS grafts were significantly different from veins $(\mathrm{p}<0.001)$ but not from arteries $(\mathrm{p}>$ $0.25)$.

The AIx was: for vein grafts, $3.64 \pm 2.04 \%$; for SIS grafts, $13.93 \pm 7.25 \%$, and for arteries, $30.49 \pm 4.16 \%$. SIS grafts had a significantly higher AIx than veins ( $\mathrm{p}<$ $0.002)$ but a lower AIx than arteries $(\mathrm{p}<0.001)$. The Em was: veins, $6.91 \pm 4.37 \mathrm{~mm} \mathrm{Hg}(\mathrm{n}=3)$; SIS grafts, 16.51 $\pm 5.33 \mathrm{~mm} \mathrm{Hg}(\mathrm{n}=6)$, and arteries, $82.33 \pm 33.76 \mathrm{~mm}$ $\mathrm{Hg}(\mathrm{n}=3)$. SIS grafts had a higher Em than veins $(\mathrm{p}<$ $0.04)$ but a lower Em than arteries $(\mathrm{p}<0.02)$.

\section{Comparison of Luminal Thrombosis by Gross}

Morphology, Histology and Immunostaining

We observed minimum thrombus formation on endothelialized SIS grafts (fig. 6a, b). Considerable thrombus was formed on SIS grafts without endothelial cell seeding (fig. 6c). Native autologous carotid arteries and jugular veins were used as positive controls and presented a smooth shiny surface with no visible thrombus formation (fig. $6 \mathrm{~d}, \mathrm{e}$ ). Gross morphology was verified by histological analysis of tissue sections showing a single layer of BAECs with few platelets attached on the luminal surface of static (fig. 6f) or shear preconditioned (fig. 6g) endothelial cell-seeded grafts. In the shear preconditioned SIS grafts, the nucleus of BAECS appeared smaller, probably due to the cell alignment in the direction of flow (fig. $6 \mathrm{~g}$ ). In contrast, in the absence of endothelial cells, red blood cells, and fibrin clots could be easily visualized on the luminal surface of the grafts (fig. 6h). As expected, the jugular vein and carotid artery presented a homogeneous layer of endothelial cells with no evidence of thrombus formation (fig. 6i, j).

Since individual platelets have an average size of 2.0 $\mu \mathrm{m}$ and are difficult to visualize by histology, we em- 
Fig. 5. Vascular stiffness measurement using PWV, AIx, and Em. a-c Jugular veins. d-f SIS grafts. g-i Carotid arteries. a, d, g Pressure wave form. b, e, $\mathbf{h}$ Magnification of the pressure wave peak is used to calculate the AIx. c, f, i Dynamic diameter change. Ps = Systolic pressure; $\mathrm{Pd}=$ diastolic pressure; $\mathrm{Pi}=$ inflection point that indicates the beginning upstroke of the reflected pressure wave; $\mathrm{T}_{\mathrm{A}}=$ time corresponding to the pressure foot (point A); $\mathrm{T}_{\mathrm{A}^{\prime}}=$ time at point $\mathrm{A}^{\prime} . \mathrm{PT}=$ Pressure transducer, LED = LED micrometer. For each graft PWV represents the average of 2-3 waveforms.
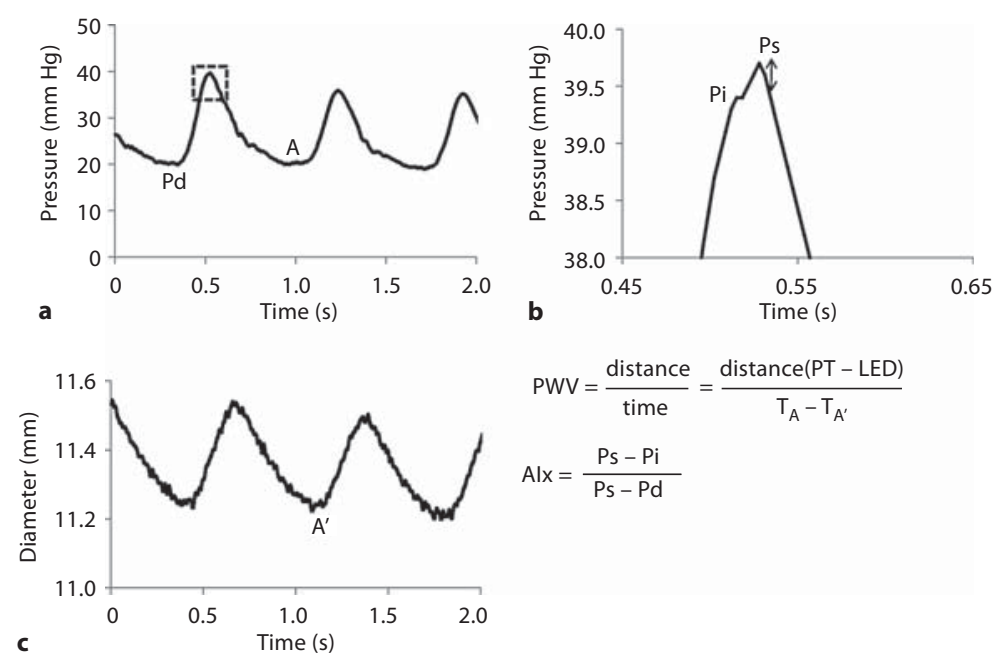

$P W V=\frac{\text { distance }}{\text { time }}=\frac{\text { distance }(P T-L E D)}{T_{A}-T_{A^{\prime}}}$

$A l x=\frac{P s-P i}{P s-P d}$
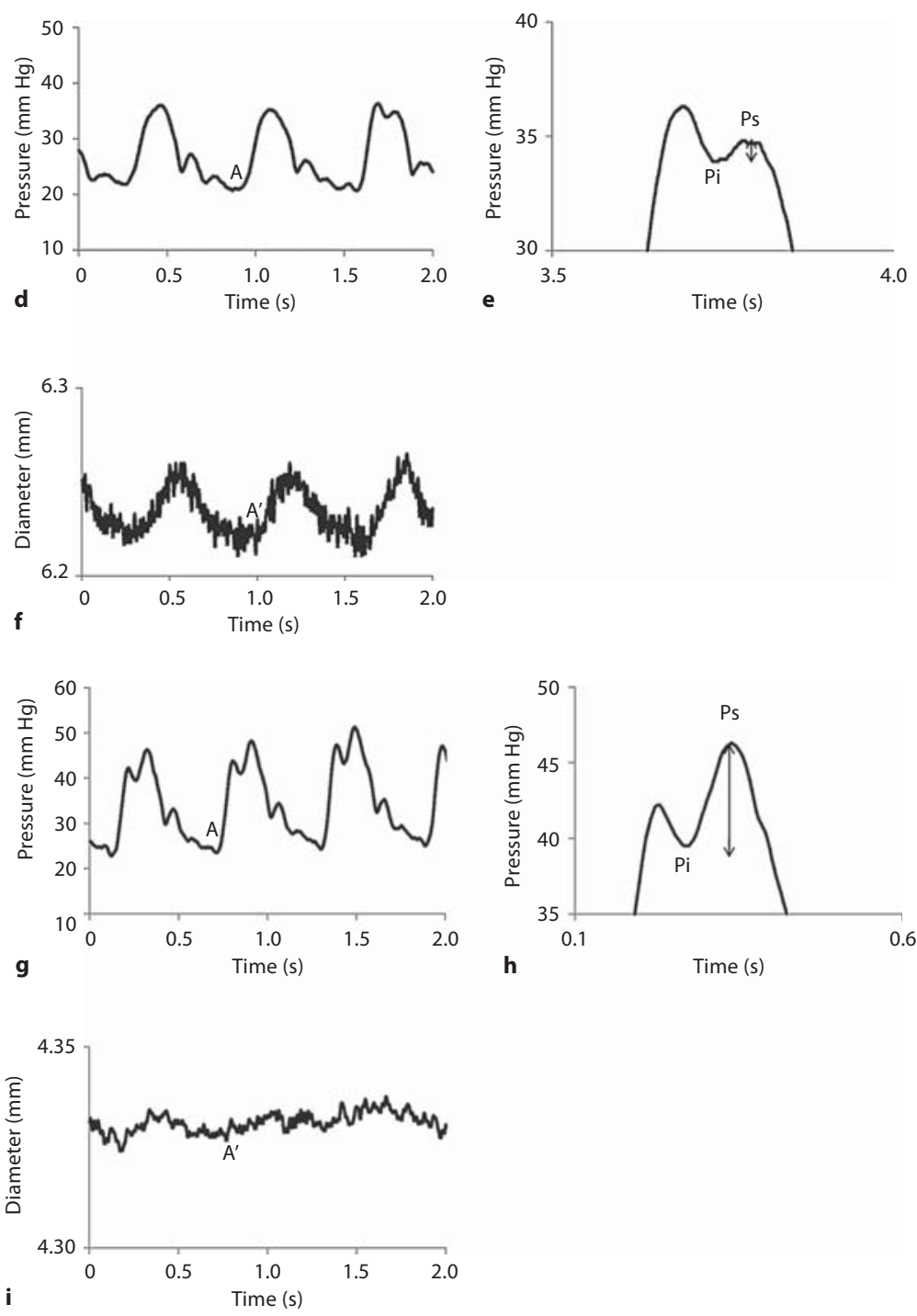


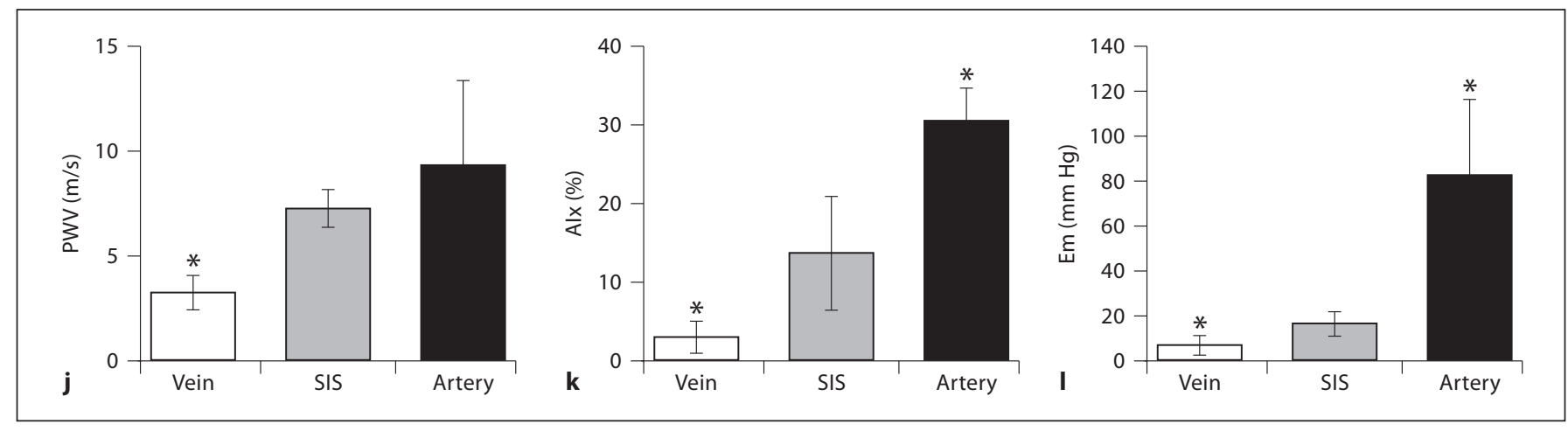

Fig. 5. Vascular stiffness measurement using PWV, AIx, and Em. j Quantification of PWV. k Quantification of AIx. I Quantification of Em. The asterisk denotes a significant difference between the indicated sample and SIS ( $\mathrm{n}=3$ grafts). For each graft PWV represents the average of $2-3$ waveforms.

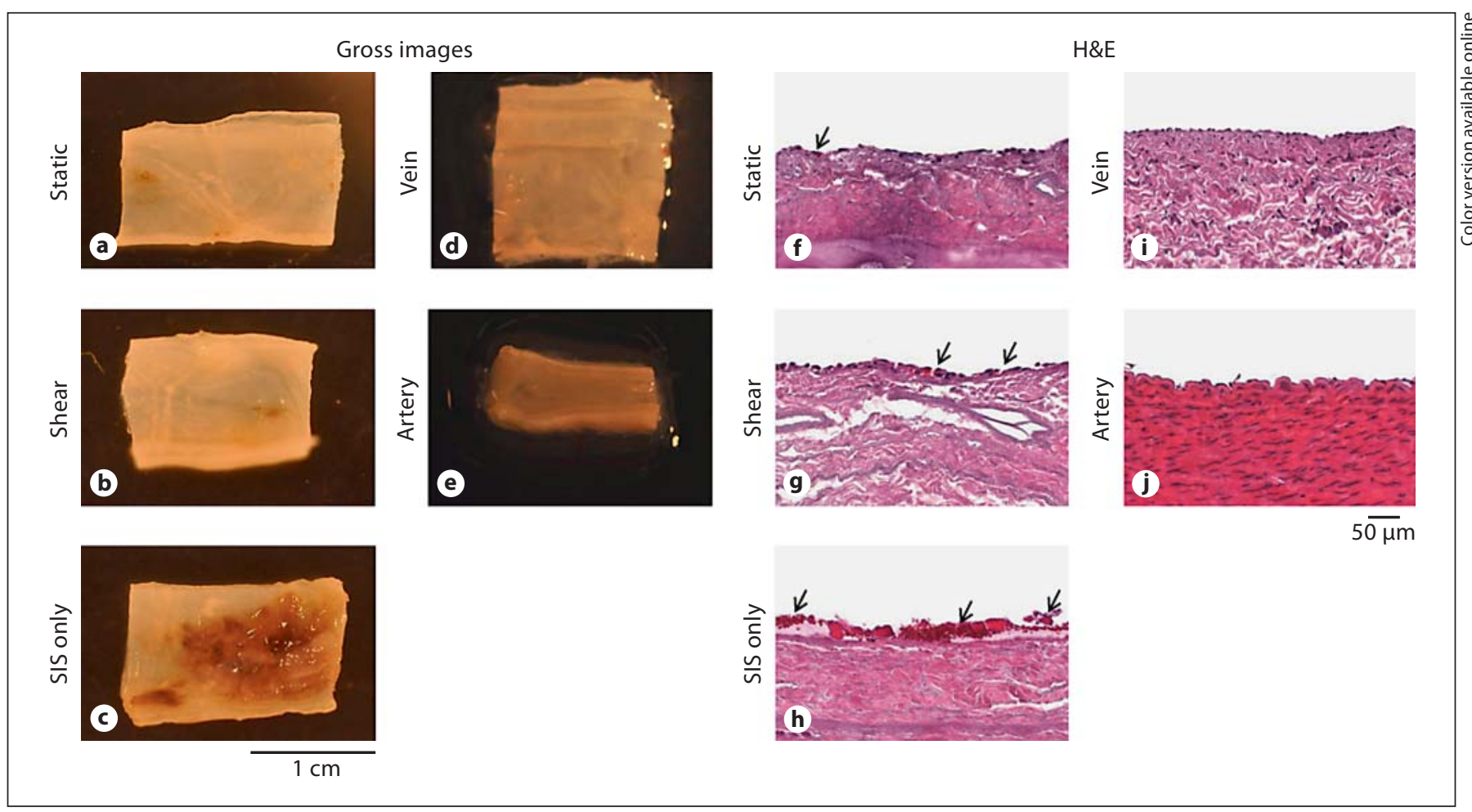

Fig. 6. SIS grafts seeded with BAECs in static or sheared conditions demonstrated coagulation deposits in gross images and histology. a, f Static BAEC-seeded grafts. b, $\mathbf{g}$ Sheared BAEC-seeded grafts. $\mathbf{c}, \mathbf{h}$ SIS only. $\mathbf{d}$, i Jugular vein. e, j Carotid artery. Scale bars $=1 \mathrm{~cm}$ $(\mathbf{a}-\mathbf{e})$ and $50 \mu \mathrm{m}(\mathbf{f}-\mathbf{h})$. The arrows point to platelets or red blood cells.

ployed en face immunofluorescence staining with antiplatelet antibody CD61 (glycoprotein IIb/IIIa) to identify platelets or platelet aggregates bound to the luminal surface of the grafts. Static or presheared BAEC-seeded SIS grafts showed adhesion of individual platelets and a rela- tively lower platelet aggregate formation (fig. 7a-d). In contrast, nonendothelialized SIS demonstrated a very high degree of individual and aggregate platelet adherence (fig. 7e, f). Carotid artery and jugular vein displayed minimal platelet adhesion (fig. $7 \mathrm{~g}-\mathrm{j}$ ). 


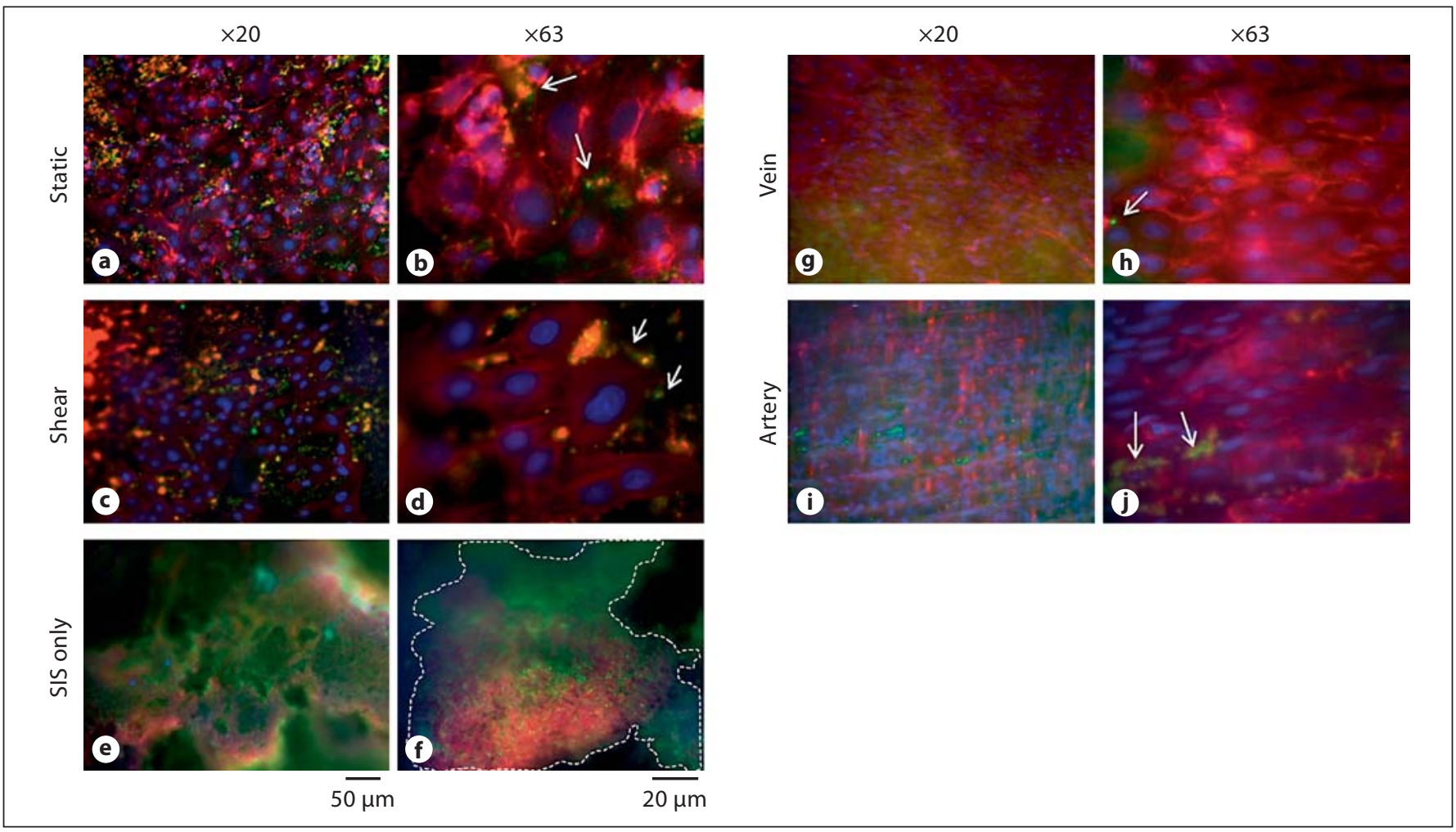

Fig. 7. The endothelialized surface of grafts exhibited better antithrombogenic properties. Platelets on the surface of grafts were stained with anti-CD61 (green) to identify platelets. Hoechst (blue) and phalloidin Alexa 546 (red). a, b Static culture: some individual platelets. c, d Shear condition: platelets were seen at the intercellular area; e, f SIS only: without endothelial cells large

\section{SEM Analysis}

Similar to histology and immunostaining, SEM analysis showed that static and shear preconditioned endothelialized grafts (fig. 8a-d) had very little platelet and red blood cell deposition as compared to nonendothelialized grafts (fig. 8e, f). Presheared BAECs appeared aligned in the direction of flow and displayed better defined cell-cell contacts than static grafts. The nonendothelialized SIS surfaces clearly revealed adhesion of platelets, red blood cells, and fibrin mesh onto a large fraction of the surface. Notably, in SEM thrombi are more luminescent and can be easily distinguished from cells.

Finally, as shown in figure $8 \mathrm{k}$, quantification of the area covered by platelets revealed that the presence of endothelial cells significantly decreased the platelet coverage on the surface (SIS grafts only: $58.2 \pm 11.66 \%$; SIS grafts with static endothelial cell culture: $8.98 \pm 6.24 \%$; SIS grafts with shear endothelial cell culture: $12.40 \pm$ platelet aggregates were observed throughout the lumen of the grafts. The platelet aggregate is circled. $\mathbf{g}$, $\mathbf{h}$ Jugular vein: minimum platelet adhesion. $\mathbf{i}, \mathbf{j}$ Carotid artery: minimum platelet adhesion. Arrows indicate platelets. Scale bars $=50 \mu \mathrm{m}(\mathbf{a}, \mathbf{c}, \mathbf{e}, \mathbf{g}, \mathbf{i})$ and $20 \mu \mathrm{m}(\mathbf{b}, \mathbf{d}, \mathbf{f}, \mathbf{h}, \mathbf{j})$.
7.53, $\mathrm{p}<0.001)$ but preconditioning with shear did not result in a significantly different platelet adhesion as compared to static ( $p>0.05)$. Native carotid artery and jugular vein were tested as the positive controls of the assay. The minimal platelet attachment to native vessels (carotid artery: $2.70 \pm 1.64 \%$; jugular vein: $0.66 \pm 0.41 \%$ ) may reflect activation due to injury at harvest or incomplete washing. Each data point was the result of analysis from 3 different samples, with a total of 5 images.

\section{Limitation of the Model}

The blood flow rate was maintained between 200 and $300 \mathrm{ml} / \mathrm{min}$ using a downstream restrictor and the pressure varied with the level of restrictor regulation but remained between 40 and $60 \mathrm{~mm} \mathrm{Hg}$. Since the PWV, AIx and Em are pressure dependent, their levels may be lower in our model system compared to those in the arterial circulation (5-15 m/s) [Jiang et al., 2008]. 


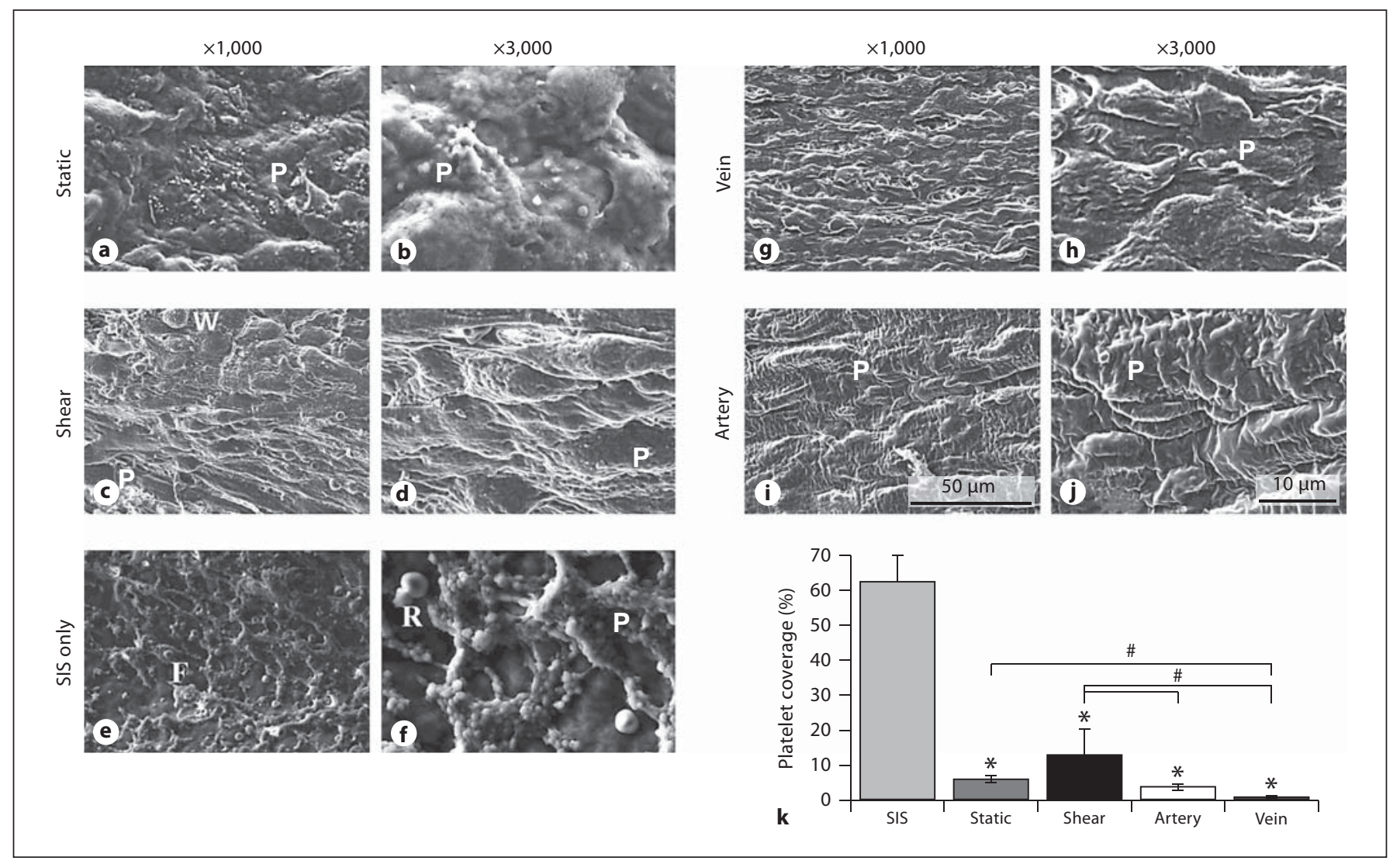

Fig. 8. Endothelialization of the grafts reduced luminal coagulation. SEM images of the graft lumen. Platelets, red blood cells, white blood cells, and fibrin mesh can be clearly visualized and distinguished. Severe coagulation was observed throughout the cell-free surface of SIS. a, b Static. c, $\mathbf{d}$ Sheared. e, $\mathbf{f}$ SIS only. $\mathbf{g}, \mathbf{h}$ Jugular vein. i, j Carotid artery. $\mathbf{k}$ Quantification of the luminal area that was covered by platelets at the indicated conditions. $\mathrm{P}=$ Platelets; $\mathrm{W}=$ white blood cells; $\mathrm{R}=$ red blood cells; $\mathrm{F}=$ fibrin mesh. The asterisk denotes a significant difference as compared to the SIS-only surface. ${ }^{\#}$ denotes a significant difference between the indicated grafts $(n=3, p<0.05)$.

\section{Discussion}

Surface coating, endothelialization, and/or preconditioning to mimic the native vessel microenvironment can decrease platelet attachment and improve graft patency [Aoki et al., 2005; Hoenig et al., 2005; Desai et al., 2011]. Regardless of the materials or cells used to engineer vascular grafts, low thrombogenicity, limited intimal hyperplasia, and the capacity of extracellular matrix remodeling after implantation are key variables for a successful implantation [Stegemann et al., 2007; Chlupac et al., 2009]. Here we developed an ex vivo arteriovenous shunt model to test the thrombogenicity and stiffness of the SIS grafts when optimizing endothelial cell seeding, mechanical preconditioning and anticoagulation therapy. Through the use of a downstream restrictor, flow meter, and pressure transducer we were able to manually control the physical environment by altering the flow and pressure to an arterial- or venous-like level. In this study we focused on the arterial environment because we aimed to implant an arterial substitute and coagulation is heavily shear dependent.

Combination drug therapy is used to prevent and maintain a safe level of anticoagulation and prevent immune reaction. Cyclosporine causes adverse effects on the intravascular hemostatic equilibrium, favoring a prothrombotic state by decreasing the release of prostacyclin and nitric oxide (NO) while increasing the production of thromboxane A2 and endothelin by endothelial cells [Conger et al., 1994]. Cyclosporine also affects platelets by increasing their surface fibrinogen receptors, enhancing serotonin release and making them hyperaggregable in 
response to various agonists [Fishman et al., 1991]. Warfarin sodium is a coumarin anticoagulant used to treat and prevent thromboembolic events by slowing the hepatic vitamin K-dependent synthesis of prothrombin and other coagulation factors [Lippi et al., 2009]. Warfarin sodium acts indirectly and has no effect on existing clots. Heparin is an intravenous anticoagulant that is often administered using a weight-based protocol as a bolus injection followed by continuous intravenous administration [Salamonson, 2000]. The onset of its action is immediate and its half-life is much shorter than that of warfarin sodium. Finally, aspirin inhibits platelet activity by preventing adhesion, aggregation, and activation. In this study, we used clinically relevant doses of each drug as determined by aPTT and INR measurements to maintain recommended blood coagulation times.

The stiffness of the grafts is believed to affect the longterm cellular infiltration, proliferation, and remodeling potential in vivo [Abbott et al., 1987; Jacot et al., 2004; Li et al., 2008]. We measured three indicators of blood vessel stiffness in real time while the grafts were in the arteriovenous loop: PWV, AIx, and Em. PWV uses pressure waves at two sites, usually the carotid and radial or carotid and femoral pulses, to calculate the pulse wave propagation velocity [Oliver and Webb, 2003]. The AIx is calculated independently of the diameter of the grafts, which gave us another window to evaluate the vascular stiffness, while Em is derived from pressure and diameter changes. All three different approaches had similar results, namely that SIS-based grafts exhibited a stiffness between that of carotid artery and jugular vein. PWV measurements showed that the stiffness of SIS grafts was higher than that of veins but similar to that of carotid arteries, suggesting that SIS grafts may exhibit satisfactory remodeling as arterial grafts. However, the AIx and Em showed that SIS stiffness was higher than venous stiffness but significantly lower than arterial stiffness. The reason for this discrepancy between the different indicators is not clear but it may reflect the lack of smooth muscle cells and basal tone as well as differences in extracellular matrix composition in the wall of SIS grafts. In the future PWV and the AIx can be applied to monitor the graft remodeling potential after implantation.

Initially we were hoping to monitor the change in flow rate and/or magnitude of pulsation as a function of thrombus formation over time. This hypothesis was based on a mouse model, in which we observed total occlusion of the carotid artery within 20 min after denudation of endothelial layer by ferric chloride (data not shown) [Surin et al., 2010]. However, we did not see a sig- nificant correlation between flow rate and pulsation with thrombus formation. Histological inspection of the blood flow-exposed SIS grafts with no cells showed that there was no more than $200 \mu \mathrm{m}$ of thrombus formation on the surface, which accounts for less than $5 \%$ of the inner diameter $(4 \mathrm{~mm})$. Thus, the luminal constriction due to thrombus formation is relatively negligible within the time frame of the experiment, necessitating morphological and histological examination to evaluate thrombus formation.

Previous studies showed that arterial implantation of SIS-based conduits revealed good patency, cell infiltration, and matrix remodeling of vascular grafts resulting in vasoreactive conduits [Huynh et al., 1999]. However, long-term implantation of cell-free SIS conduits in the arterial circulation showed aneurysm formation and vascular expansions possibly due to thrombosis and matrix degradation [Pavcnik et al., 2009]. Our experiments showed significant platelet attachment on the surface of cell-free SIS within minutes even after treatment with a clinical dose of heparin and warfarin sodium, suggesting that endothelialization is necessary for the development of implantable vascular grafts. Surprisingly, we found that preconditioning with flow-induced shear did not improve patency further. Several factors may explain these results. First, in our bioreactor shear stress was limited to 6 dynes $/ \mathrm{cm}^{2}$ because a physiological pressure was reached at that shear level. It remains to be seen whether increasing the shear stress to an arterial level (10-20 dynes $\left./ \mathrm{cm}^{2}\right)$ will decrease platelet adhesion beyond that of static culture. Second, high shear preconditioning may prevent thrombosis in the long term through NO secretion and subsequent vessel relaxation. It is possible that longer blood flow times may be required to see the effects of shear on coagulation. Finally, SEM images showed that the majority of platelets attached in the small gaps between endothelial cells either in static or presheared grafts, suggesting that complete endothelial cell coverage may be a more critical factor than shear in preventing platelet attachment, at least in the short term.

In conclusion, we established an ex vivo arteriovenous shunt model to evaluate the thrombogenicity and mechanical properties of vascular grafts in order to examine their potential for in vivo implantation. Furthermore, the model may be applied to test: (1) the coagulation response after luminal modifications by chemicals such as heparin, (2) the efficacy of anticoagulation drugs targeting a certain step of the coagulation cascade, (3) the anticoagulation potential of endothelial progenitor cells from different sources such as EPCs or induced pluripotent stem 
cells, or (4) the dynamic compliance and mechanical properties of grafts prepared from different matrix materials or in the presence of smooth muscle cells in the vessel wall. Currently, we are using this model to evaluate the mechanical properties of SIS grafts containing hair follicle stem cell-derived smooth muscle cells [Peng et al., $2010 \mathrm{~b}]$ in the vessel wall and the long-term patency and remodeling of these grafts in vivo.

\section{Acknowledgements}

This work was supported by grants from the National Institutes of Health (R01 HL086582) and the New York State Stem Cell Science Foundation (NYSTEM; contract No. C024316) to S.T. Andreadis and D.D. Swartz.

\section{References}

Abbott, W.M., J. Megerman, J.E. Hasson, G. L'Italien, D.F. Warnock (1987) Effect of compliance mismatch on vascular graft patency. J Vasc Surg 5: 376-382.

Aoki, J., P.W. Serruys, H. van Beusekom, A.T. Ong, E.P. McFadden, G. Sianos, W.J. van der Giessen, E. Regar, P.J. de Feyter, H.R. Davis, S. Rowland, M.J. Kutryk (2005) Endothelial progenitor cell capture by stents coated with antibody against CD34: the HEALING-FIM (Healthy Endothelial Accelerated Lining Inhibits Neointimal Growth-First In Man) Registry. J Am Coll Cardiol 45: 1574-1579.

Baguet, J.P., B.A. Kingwell, A.L. Dart, J. Shaw, K.E. Ferrier, G.L. Jennings (2003) Analysis of the regional pulse wave velocity by Doppler: methodology and reproducibility. J Hum Hypertens 17: 407-412.

Brass, L.F., L. Zhu, T.J. Stalker (2008) Novel therapeutic targets at the platelet vascular interface. Arterioscler Thromb Vasc Biol 28: s4350.

Chin-Quee, S.L., S.H. Hsu, K.L. Nguyen-Ehrenreich, J.T. Tai, G.M. Abraham, S.D. Pacetti, Y.F. Chan, G. Nakazawa, F.D. Kolodgie, R. Virmani, N.N. Ding, L.A. Coleman (2009) Endothelial cell recovery, acute thrombogenicity, and monocyte adhesion and activation on fluorinated copolymer and phosphorylcholine polymer stent coatings. Biomaterials 31: 648-657.

-Chlupac, J., E. Filova, L. Bacakova (2009) Blood vessel replacement: 50 years of development and tissue engineering paradigms in vascular surgery. Physiol Res 58(suppl 2): S119139.

Conger, J.D., G.E. Kim, J.B. Robinette (1994) Effects of ANG II, ETA, and TxA2 receptor antagonists on cyclosporin A renal vasoconstriction. Am J Physiol 267: F443-449.

-Conklin, B.S., E.R. Richter, K.L. Kreutziger, D.S. Zhong, C. Chen (2002) Development and evaluation of a novel decellularized vascular xenograft. Med Eng Phys 24: 173-183.

Connell, J.M., T. Khalapyan, H.A. Al-Mondhiry, R.P. Wilson, G. Rosenberg, W.J. Weiss (2007) Anticoagulation of juvenile sheep and goats with heparin, warfarin, and clopidogrel. ASAIO J 53: 229-237.
Dahl, S.L., A.P. Kypson, J.H. Lawson, J.L. Blum, J.T. Strader, Y. Li, R.J. Manson, W.E. Tente, L. DiBernardo, M.T. Hensley, R. Carter, T.P. Williams, H.L. Prichard, M.S. Dey, K.G. Begelman, L.E. Niklason (2011) Readily available tissue-engineered vascular grafts. Sci Transl Med 3: 68ra69.

Desai, M., A.M. Seifalian, G. Hamilton (2011) Role of prosthetic conduits in coronary artery bypass grafting. Eur J Cardiothorac Surg 40: 394-398.

-Fishman, S.J., L.J. Wylonis, J.D. Glickman, J.J. Cook, D.S. Warsaw, C.A. Fisher, D.J. Jorkasky, S. Niewiarowski, V.P. Addonizio (1991) Cyclosporin A augments human platelet sensitivity to aggregating agents by increasing fibrinogen receptor availability. J Surg Res 51: 93-98.

Geer, D.J., D.D. Swartz, S.T. Andreadis (2004) In vivo model of wound healing based on transplanted tissue-engineered skin. Tissue Eng 10: 1006-1017.

Grines, C.L., R.O. Bonow, D.E. Casey Jr, T.J. Gardner, P.B. Lockhart, D.J. Moliterno, P. O'Gara, P. Whitlow (2007) Prevention of premature discontinuation of dual antiplatelet therapy in patients with coronary artery stents: a science advisory from the American Heart Association, American College of Cardiology, Society for Cardiovascular Angiography and Interventions, American College of Surgeons, and American Dental Association, with representation from the American College of Physicians. J Am Dent Assoc 138: 652-655.

Gui, L., A. Muto, S.A. Chan, C.K. Breuer, L.E. Niklason (2009) Development of decellularized human umbilical arteries as small-diameter vascular grafts. Tissue Eng Part A 15: 2665-2676.

Hashi, C.K., N. Derugin, R.R. Janairo, R. Lee, D. Schultz, J. Lotz, S. Li (2010) Antithrombogenic modification of small-diameter microfibrous vascular grafts. Arterioscler Thromb Vasc Biol 30: 1621-1627.

Hingorani, A., E. Ascher, N. Marks (2007) Preprocedural imaging: new options to reduce need for contrast angiography. Semin Vasc Surg 20: 15-28.
Hoenig, M.R., G.R. Campbell, B.E. Rolfe, J.H. Campbell (2005) Tissue-engineered blood vessels: alternative to autologous grafts? Arterioscler Thromb Vasc Biol 25: 1128-1134.

Huynh, T., G. Abraham, J. Murray, K. Brockbank, P.O. Hagen, S. Sullivan (1999) Remodeling of an acellular collagen graft into a physiologically responsive neovessel. Nat Biotechnol 17: 1083-1086.

-Inauen, W., H.R. Baumgartner, T. Bombeli, A. Haeberli, P.W. Straub (1990) Dose- and shear rate-dependent effects of heparin on thrombogenesis induced by rabbit aorta subendothelium exposed to flowing human blood. Arteriosclerosis 10: 607-615.

Isenberg, B.C., C. Williams, R.T. Tranquillo (2006) Small-diameter artificial arteries engineered in vitro. Circ Res 98: 25-35.

Jacot, J.G., I. Abdullah, M. Belkin, M. GerhardHerman, P. Gaccione, J.F. Polak, M.C. Donaldson, A.D. Whittemore, M.S. Conte (2004) Early adaptation of human lower extremity vein grafts: wall stiffness changes accompany geometric remodeling. J Vasc Surg 39: 547-555.

Jiang, B., B. Liu, K.L. McNeill, P.J. Chowienczyk (2008) Measurement of pulse wave velocity using pulse wave Doppler ultrasound: comparison with arterial tonometry. Ultrasound Med Biol 34: 509-512.

Kannan, R.Y., K.M. Sales, H.J. Salacinski, P.E. Butler, A.M. Seifalian (2004) Endothelialisation of poly (carbonate-siloxane-urea) urethane. Med J Malaysia 59(suppl B): 107-108.

Lane, H.A., J.C. Smith, J.S. Davies (2006) Noninvasive assessment of preclinical atherosclerosis. Vasc Health Risk Manag 2: 19-30.

Li, L., C.M. Terry, Y.T. Shiu, A.K. Cheung (2008) Neointimal hyperplasia associated with synthetic hemodialysis grafts. Kidney Int 74: 1247-1261.

Lin, P.H., C. Chen, R.L. Bush, Q. Yao, A.B. Lumsden, S.R. Hanson (2004) Small-caliber heparin-coated ePTFE grafts reduce platelet deposition and neointimal hyperplasia in a baboon model. J Vasc Surg 39: 1322-1328.

Lippi, G., M. Franchini, E.J. Favaloro (2009) Pharmacogenetics of vitamin K antagonists: useful or hype? Clin Chem Lab Med 47: 503515. 
Liu, J.Y., H.F. Peng, S.T. Andreadis (2008) Contractile smooth muscle cells derived from hair-follicle stem cells. Cardiovasc Res 79: 24-33.

Martins, G.G., J. Kolega (2006) Endothelial cell protrusion and migration in three-dimensional collagen matrices. Cell Motil Cytoskeleton 63: 101-115.

Nemcova, S., A.A. Noel, C.J. Jost, P. Gloviczki, V.M. Miller, K.G. Brockbank (2001) Evaluation of a xenogeneic acellular collagen matrix as a small-diameter vascular graft in dogs-preliminary observations. J Invest Surg 14: 321-330.

Nichols, W.W. (2005) Clinical measurement of arterial stiffness obtained from noninvasive pressure waveforms. Am J Hypertens 18: 3S$10 \mathrm{~S}$.

Nichols, W.W., S.J. Denardo, I.B. Wilkinson, C.M. McEniery, J. Cockcroft, M.F. O'Rourke (2008) Effects of arterial stiffness, pulse wave velocity, and wave reflections on the central aortic pressure waveform. J Clin Hypertens (Greenwich) 10: 295-303.

-Oliver, J.J., D.J. Webb (2003) Noninvasive assessment of arterial stiffness and risk of atherosclerotic events. Arterioscler Thromb Vasc Biol 23: 554-566.

- Pavcnik, D., J. Obermiller, B.T. Uchida, W. Van Alstine, J.M. Edwards, G.J. Landry, J.A. Kaufman, F.S. Keller, J. Rosch (2009) Angiographic evaluation of carotid artery grafting with prefabricated small-diameter, small-intestinal submucosa grafts in sheep. Cardiovasc Intervent Radiol 32: 106-113.

Peng, H.F., J.Y. Liu, S.T. Andreadis, D.D. Swartz (2010b) Hair follicle-derived smooth muscle cells and small intestinal submucosa for engineering mechanically robust and vasoreactive vascular media. Tissue Eng Part A 17: 981-990.

Peng, A., R.M. Straubinger, S.V. Balu-Iyer (2010a) Phosphatidylinositol containing lipidic particles reduces immunogenicity and catabolism of factor VIII in hemophilia a mice. AAPS J 12: 473-481.
Robotin-Johnson, M.C., P.E. Swanson, D.C. Johnson, R.B. Schuessler, J.L. Cox (1998) An experimental model of small intestinal submucosa as a growing vascular graft. J Thorac Cardiovasc Surg 116: 805-811.

Salacinski, H.J., G. Punshon, B. Krijgsman, G. Hamilton, A.M. Seifalian (2001) A hybrid compliant vascular graft seeded with microvascular endothelial cells extracted from human omentum. Artif Organs 25: 974-982.

Salamonson, Y. (2000) The ineffectiveness of a non-weight based heparin regimen in achieving therapeutic activated partial thromboplastin time (aPTT) in acute coronary syndrome. Aust Crit Care 13: 128-133.

Sanz, J., M. Kariisa, S. Dellegrottaglie, S. PratGonzalez, M.J. Garcia, V. Fuster, S. Rajagopalan (2009) Evaluation of pulmonary artery stiffness in pulmonary hypertension with cardiac magnetic resonance. JACC Cardiovasc Imaging 2: 286-295.

Seifalian, A.M., H.J. Salacinski, A. Tiwari, A. Edwards, S. Bowald, G. Hamilton (2003) In vivo biostability of a poly(carbonate-urea)urethane graft. Biomaterials 24: 2549-2557.

Shaikh, F.M., A. Callanan, E.G. Kavanagh, P.E. Burke, P.A. Grace, T.M. McGloughlin (2008) Fibrin: a natural biodegradable scaffold in vascular tissue engineering. Cells Tissues Organs 188: 333-346.

Stegemann, J.P., S.N. Kaszuba, S.L. Rowe (2007) Review: advances in vascular tissue engineering using protein-based biomaterials. Tissue Eng 13: 2601-2613.

Surin, W.R., P. Prakash, M.K. Barthwal, M. Dikshit (2010) Optimization of ferric chloride induced thrombosis model in rats: effect of anti-platelet and anti-coagulant drugs. J Pharmacol Toxicol Methods 61: 287-291.

Swartz, D.D., J.A. Russell, S.T. Andreadis (2005) Engineering of fibrin-based functional and implantable small-diameter blood vessels. Am J Physiol Heart Circ Physiol 288: H14511460.

Tepe, G., J. Schmehl, H.P. Wendel, S. Schaffner, S. Heller, M. Gianotti, C.D. Claussen, S.H Duda (2006) Reduced thrombogenicity of nitinol stents - in vitro evaluation of different surface modifications and coatings. Biomaterials 27: 643-650.
Tiwari, A., H.J. Salacinski, G. Punshon, G. Hamilton, A.M. Seifalian (2002) Development of a hybrid cardiovascular graft using a tissue engineering approach. FASEB J 16: 791-796.

Torikai, K., H. Ichikawa, K. Hirakawa, G. Matsumiya, T. Kuratani, S. Iwai, A. Saito, N. Kawaguchi, N. Matsuura, Y. Sawa (2008) A self-renewing, tissue-engineered vascular graft for arterial reconstruction. J Thorac Cardiovasc Surg 136: 37-45, 45.e31.

Tottey, S., S.A. Johnson, P.M. Crapo, J.E. Reing, L. Zhang, H. Jiang, C.J. Medberry, B. Reines, S.F. Badylak (2010) The effect of source animal age upon extracellular matrix scaffold properties. Biomaterials 32: 128-136.

Vara, D.S., H.J. Salacinski, R.Y. Kannan, L. Bordenave, G. Hamilton, A.M. Seifalian (2005) Cardiovascular tissue engineering: state of the art. Pathol Biol (Paris) 53: 599-612.

Wu, B., B. Gerlitz, B.W. Grinnell, M.E. Meyerhoff (2007) Polymeric coatings that mimic the endothelium: combining nitric oxide release with surface-bound active thrombomodulin and heparin. Biomaterials 28: 4047-4055

Yao, L., J. Liu, S.T. Andreadis (2008) Composite fibrin scaffolds increase mechanical strength and preserve contractility of tissue engineered blood vessels. Pharm Res 25: 12121221.

Yao, L., D.D. Swartz, S.F. Gugino, J.A. Russell, S.T. Andreadis (2005) Fibrin-based tissueengineered blood vessels: differential effects of biomaterial and culture parameters on mechanical strength and vascular reactivity. Tissue Eng 11: 991-1003.

Yazdani, S.K., B.W. Tillman, J.L. Berry, S. Soker, R.L. Geary (2010) The fate of an endothelium layer after preconditioning. J Vasc Surg 51: 174-183.

Yoshikai, M., T. Itoh, K. Kamohara, J. Yunoki, H. Fumoto (2007) Intimal injury of ultrasonically skeletonized internal thoracic artery by a vessel clamp: morphological analysis. Interact Cardiovasc Thorac Surg 6: 331-334. 